\title{
Potentials of Steel Fibres for Mesh Mould Elements
}

\section{Conference Paper}

Author(s):

Pfändler, Patrick; Wangler, Timothy; Mata Falcón, Jaime (D); Flatt, Robert J.; Kaufmann, Walter (D)

Publication date:

2018-09

Permanent link:

https://doi.org/10.3929/ethz-b-000297641

Rights / license:

In Copyright - Non-Commercial Use Permitted

Originally published in:

RILEM Bookseries 19, https://doi.org/10.1007/978-3-319-99519-9_19 


\title{
Potentials of steel fibres for Mesh Mould elements
}

\author{
P. Pfändler ${ }^{1}$, T. Wangler ${ }^{1}$, J. Mata-Falcón ${ }^{1}$, R. J. Flatt ${ }^{1}$, W. Kaufmann ${ }^{1}$ \\ ${ }^{1}$ ETH Zurich, Zurich, Switzerland \\ patrick.pfaendler@ifb.baug.ethz.ch
}

\begin{abstract}
Mesh Mould is a digital fabrication technique developed at ETH Zurich in which the reinforcement and formwork production are unified in a robotically controlled system. An industrial robot fabricates a dense, three-dimensional, double-sided, welded reinforcement mesh that is infilled with a special concrete mix that achieves sufficient compaction without flowing out the mesh, which acts as porous formwork. Since the project started in 2012, the actual generation of robot end-effector is capable of bending and welding conventional steel reinforcement of 6 and $4.5 \mathrm{~mm}$ in diameter. Due to the process, the load-bearing capacity of these Mesh Mould elements is not equal in both directions due to geometrical restrictions in the end-effector. This study aims to increase the loadbearing capacity in the weaker direction by using steel fibre reinforced concrete (SFRC), which orients the fibres during flowing in this direction and in addition prevents the leakage of the concrete by enhancing jamming. A total of 10 specimens with $540 \times 210 \times 80 \mathrm{~mm}$ dimensions were tested in a displacement controlled symmetric four-point bending test. By combining SFRC with a mesh, the bending strength increased significantly with respect to the samples without fibres. The capacity is higher than the capacity of the individual parts, which are evaluated in separate material tests. Nonetheless, the bending strength in this study was limited by the weld strength, which was considerably lower than the one achieved by the robot. Higher weld strength would lead to better performance than in this first study, which is a part of an ongoing research effort.
\end{abstract}

Keywords: Mesh Mould, Steel fibre reinforced concrete SFRC, digital reinforcement assemblies, digital construction

\section{Introduction}

\subsection{Background about the Mesh Mould project}

The Mesh Mould project started in 2012 at ETH Zurich to explore the possibilities of digitally fabricating concrete structures with high geometric complexity without conventional moulds. The project started with a customized tool-head to build a polymer network through a spatial extrusion process with a rather low tensile strength of the polymer. At that time, the focus was on the shape rather than on the structural strength and led to a patent [1]. After this initial conceptual development, the project addressed the structural behaviour of the built elements and the polymer mesh was replaced by a 
steel reinforcement mesh in order to reach load-bearing capacity. The end-effector was adjusted in two steps to be able to build meshes with conventional steel reinforcement of $\varnothing 4.5$ and $\varnothing 6.0 \mathrm{~mm}$ [2]. The reinforcement mesh is composed of continuous $\varnothing 6 \mathrm{~mm}$ rebars connected by short welded $\varnothing 4.5 \mathrm{~mm}$ segments at well-defined distances controlled by the robot. The mesh acts as a porous formwork, and with a proper concrete mix design with aggregate in the order of the size of the mesh spacing, retention of the concrete can be achieved through jamming [3]. The outer surface is sprayed with an additional layer of concrete for the purpose of appearance and durability [4] (Fig. 1).

The ongoing full digitalization of civil engineering design and construction will make it possible to design concrete structures with high geometrical complexity in the individual parts of the structure. This has further possible advantages by designing concrete structures in a structurally optimal shape in favour of saving material. The invention of the Mesh Mould system might lead in the future to significantly lower costs and less waste for non-standard shapes in the building industry [5]. The first prototype of a Mesh Mould wall as the main load-bearing element was built as a part of the DFAB house in Switzerland in 2017 [6].

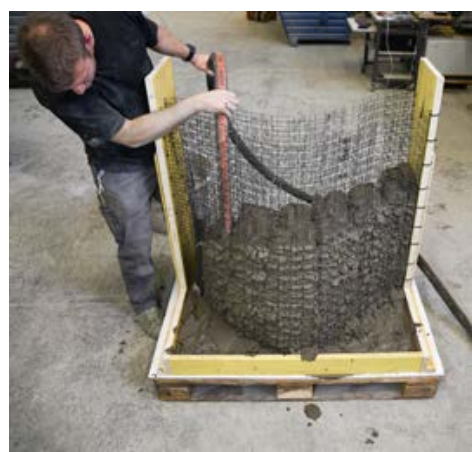

(a)

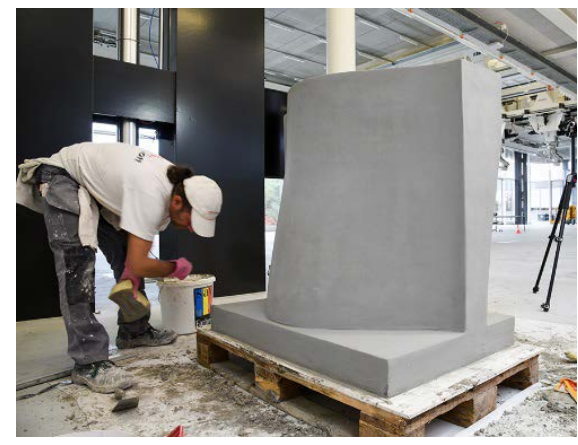

(b)

Fig. 1. (a) Concreting process of a Mesh Mould wall using a pump and (b) finishing the wall [4]

\subsection{Mechanical behaviour of Mesh Mould elements}

First exploratory experiments on the mechanical behaviour of the Mesh Mould mesh under bending loads were made by Mata-Falcón [7] on hand-made reinforcement meshes. The main observation was a very close and thin crack distribution caused by shear deformation in the continuous direction of the reinforcement mesh by the load transfer in the perpendicular direction. Figure 2 shows clearly the observation during and after the bending test and displays the mesh size of $30 \times 30 \mathrm{~mm}$. The final design of the robot end-effector cannot produce this mesh size due to geometrical constraints and as a consequence, the reinforcement content decreases substantially in the discontinuous direction [2].

The limitation of the robotic tool-head is a minimum layer distance of $30 \mathrm{~mm}$ in the continuous vertical direction and a minimum distance of $60 \mathrm{~mm}$ between two welded 
segments in the horizontal discontinuous direction, which is equal to a mesh size of $30 \times 60 \mathrm{~mm}$. The key problem is the reinforcement content in the discontinuous direction which is much weaker than in the perpendicular direction, which due to the mentioned constraints could not simply be improved by building a denser welded reinforcement mesh by the robot. In addition, this would have affected the production time for the mesh significantly.

The achievable reinforcement content could be insufficient to fulfil the requirements for a load bearing wall or even for small Mesh Mould elements subjected to bending in the weak direction. With a vertical reinforcement of Ø6@30 mm, minimum reinforcement requirements in bending are satisfied for a thickness up to $250 \mathrm{~mm}$. In the horizontal direction, however, the thickness is limited to $150 \mathrm{~mm}$ thick elements to ensure a ductile failure in bending, assuming failure of the rebars in tension.

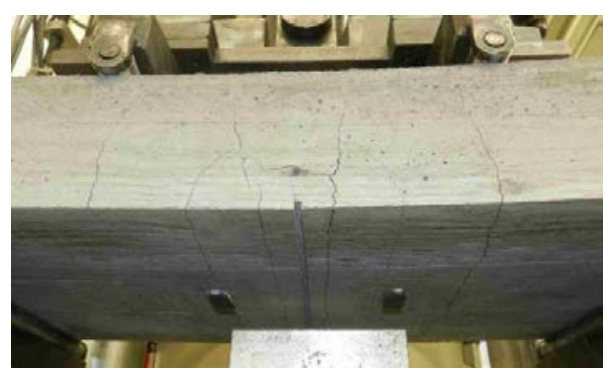

(a)

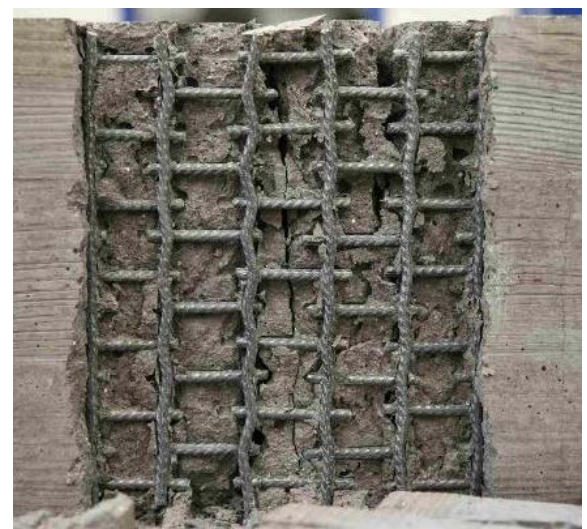

(b)

Fig. 2. (a) Notched specimen under a four-point bending test with the crack pattern and (b) view from the bottom after the bending test with shear deformation in the continuous reinforcement bars [7]

The lack of adequate continuous reinforcement in the horizontal direction limits the structural application of Mesh Mould elements to less demanding structural applications. This study aims at overcoming these limitations by the use of steel fibres oriented in the horizontal direction. During the filling process of a wall, the fibres tend to align in the horizontal direction by flowing with the concrete, which strengthens the weak direction without requiring any changes in the robot end-effector. Furthermore, the fibres reduce the leakage of concrete during the casting process thanks to jamming of the mesh.

The present study is part of an ongoing research to expand the mechanical capabilities of the Mesh Mould system in the weak direction with a view to more structurally demanding applications in the future. This paper presents a first experimental study analysing the mechanical performance of thin Mesh Mould elements with steel fibre reinforced concrete (SFRC) under flexural actions. 


\section{Experimental Program}

\subsection{Test specimens}

The objective of the experimental program was to explore the influence of steel fibres on the mechanical behaviour of Mesh Mould elements. A total of 10 specimens (see Table 1) with $540 \times 210 \times 80 \mathrm{~mm}$ dimensions were tested in a four-point bending configuration. The behaviour of concrete with and without fibres was tested for specimens reinforced with a welded mesh, which was strengthened in some cases with additional reinforcing bars. Besides these tests, additional experiments without reinforcing bars were performed in order to characterize the concrete and the SFRC material properties [8].

The welded reinforcement mesh is composed of (i) Ø6 mm rebars with $30 \mathrm{~mm}$ spacing in the direction transversal to bending and (ii) $\varnothing 5 \mathrm{~mm}$ diameter welded segments with a $60 \mathrm{~mm}$ spacing for the direction of tension. Hence, the element contains 3 to 4 reinforcing bars of $\varnothing 5 \mathrm{~mm}$ depending on the section (see Fig. 3). The mesh was welded at both ends to a steel profile to guarantee the anchorage of the reinforcement. The strengthening rebars were welded positioned between two discontinuous rebars and welded only to the steel profiles at the ends.

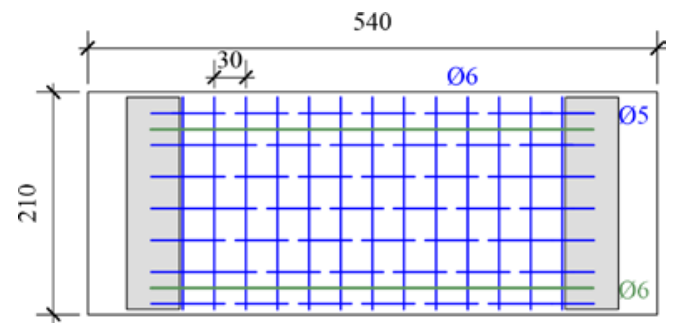

(a)

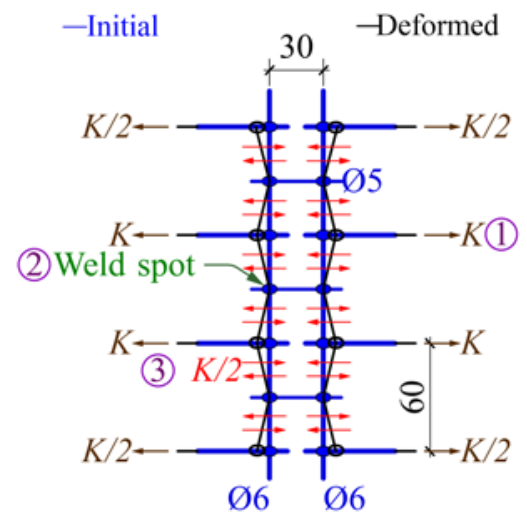

(b)

Fig. 3. (a) Tailor-made reinforcement mesh with additional strengthening and (b) Sketch of a section of the Mesh with the three possible failure modes and the shear deformation (all dimension in $[\mathrm{mm}])$

\subsection{Experimental setup}

All specimens were tested until rupture in a displacement controlled four-point bending test with $400 \mathrm{~mm}$ span and $200 \mathrm{~mm}$ distance between the loads (Fig. 4). The applied force $(F)$, the deflection $(d)$, and the crack mouth opening displacement (CMOD) at the notched midspan section were measured during the test. Moreover, pictures were taken at $0.1 \mathrm{~Hz}$ to capture the crack pattern of the specimens at different load steps. The loading speed was $0.005 \mathrm{~mm} / \mathrm{s}$ before the peak load and $0.08 \mathrm{~mm} / \mathrm{s}$ in the post-peak phase. 
The fluid self-compacting mixture influenced the fibre dispersion by the direction of the casting flow after the SFRC was poured in the middle of the mould. Moreover, the production method oriented the fibres in the direction, in which the fibres are structurally more useful. The fibre distribution along the depth of the specimens was not uniform since the concrete mix was not perfectly non-segregating, but affects the structural performance in the weaker direction again in a positive way.

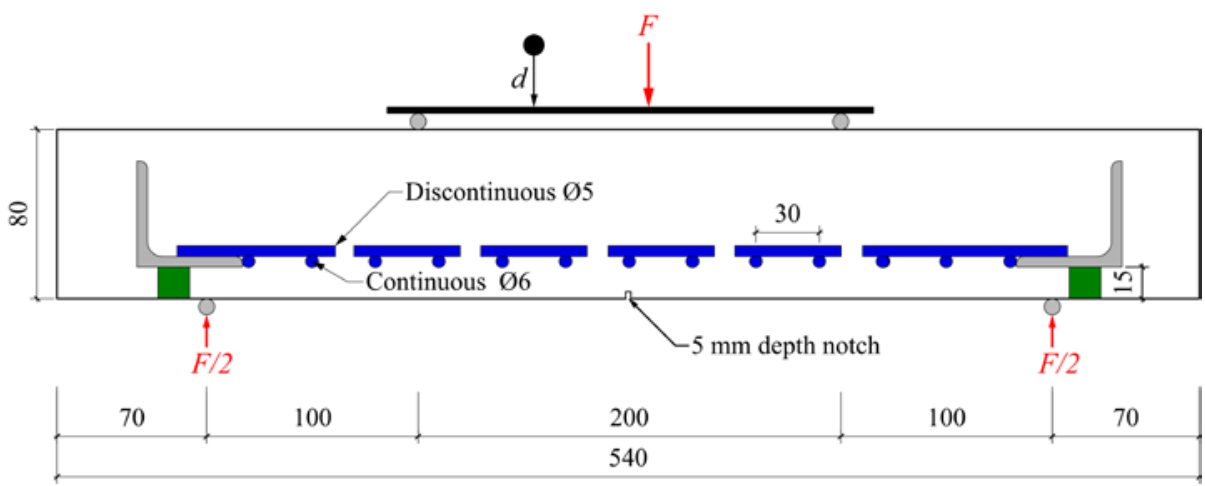

Fig. 4. Geometry and test setup (dimensions in [mm])

Table 1. Main parameters of test specimens

\begin{tabular}{|l|c|c|c|}
\hline Codification & $\begin{array}{c}\text { Number of } \\
\text { specimens }\end{array}$ & $\begin{array}{c}\text { Fibres content } \\
{[\%]}\end{array}$ & Reinforcement \\
\hline $\mathrm{C}+\mathrm{M}$ & 2 & 0.0 & Mesh \\
\hline $\mathrm{C}+\mathrm{sM}$ & 2 & 0.0 & Mesh+2Ø6 \\
\hline SFRC+M & 4 & 1.2 & Mesh \\
\hline SFRC & 2 & 1.2 & - \\
\hline
\end{tabular}

\subsection{Material properties}

Concrete. The mixture of all samples was the same despite the additional steel fibres in the SFRC mix. The concrete mixture, initially optimized for casting into 3D-sand printed elements [4], was slightly adapted for this study. The concrete had a w/c of 0.33 and a water-to-binder ratio of 0.29 , considering the amount of liquid in the superplasticizer and the reacting silica fume. The steel fibres used were straight OL 13/.16 fibres produced by Bekaert. The fibres were $0.16 \mathrm{~mm}$ in diameter and $13 \mathrm{~mm}$ long, with an ultimate tensile strength of $2^{\prime} 600 \mathrm{~N} / \mathrm{mm}^{2}$ according to the producer.

For the two mixes, the experimental setup described above was used to determine the bending strength. The mean bending capacity without any reinforcement was $1.00 \mathrm{kNm}\left(f_{c t, f l} 4.0 \mathrm{~N} / \mathrm{mm}^{2}\right)$ and $1.95 \mathrm{kNm}$ for SFRC with a volumetric content of $1.2 \%$ of fibres and a strain-hardening behaviour. Guided by DIN EN 14651 (Table 2), however using a different specimen geometry as well as the four-point test in this study, the 
flexural tensile strength was calculated at different CMODs to characterize the behaviour of the SFRC in bending.

Table 2. Overview of the results of the four-point bending test of the SFRC, where $f_{R, j}$ is the residual flexural strength at $C M O D$ of $0.5,1.5,2.5$ and $3.5 \mathrm{~mm}$ and height $h_{s p}$ which is the distance between the notch and the top of the specimen [9]

\begin{tabular}{|l|c|c|c|c|}
\hline Sample Name & $\begin{array}{c}f_{r, 1} \\
{\left[\mathrm{~N} / \mathrm{mm}^{2}\right]}\end{array}$ & $\begin{array}{c}f_{r, 2} \\
{\left[\mathrm{~N} / \mathrm{mm}^{2}\right]}\end{array}$ & $\begin{array}{c}f_{r, 3} \\
{\left[\mathrm{~N} / \mathrm{mm}^{2}\right]}\end{array}$ & $\begin{array}{c}f_{r, 4} \\
{\left[\mathrm{~N} / \mathrm{mm}^{2}\right]}\end{array}$ \\
\hline SFRC\#1 & 9.8 & 8.8 & 7.6 & $5.2^{\mathrm{a}}$ \\
\hline SFRC\#2 & 11.5 & $8.1^{\mathrm{a}}$ & $5.5^{\mathrm{a}}$ & $3.3^{\mathrm{a}}$ \\
\hline \multicolumn{2}{|c|}{ : value calculated through the linear relationship between the CMOD and the deflection $d$} \\
\hline
\end{tabular}

In addition, compression tests on a total of 8 cubes with dimensions $150 \times 150 \times 150$ mm were conducted to obtain the compressive strength between 23 and 28 days. The range of the compressive strength for concrete was between $111 \mathrm{~N} / \mathrm{mm}^{2}$ and $133 \mathrm{~N} / \mathrm{mm}^{2}$ based on 4 cubes, for the SFRC between $130 \mathrm{~N} / \mathrm{mm}^{2}$ and $143 \mathrm{~N} / \mathrm{mm}^{2}$.

Reinforcement. Table 3 shows the main properties of the reinforcement obtained from standard tensile tests. A company produced (as close as possible to the mesh produced by the robot) meshes $1000 \times 1000 \mathrm{~mm}$ in size that were cut by hand to the required shape.

Table 3. Material properties of the reinforcement

\begin{tabular}{|l|c|c|c|c|c|}
\hline & $\begin{array}{c}\varnothing \\
{[\mathrm{mm}]}\end{array}$ & $\begin{array}{c}\text { Steel type } \\
{[-]}\end{array}$ & $\begin{array}{c}\text { Yield stress } \\
f_{y}\left[\mathrm{~N} / \mathrm{mm}^{2}\right]\end{array}$ & $\begin{array}{c}\text { Ultimate stress } \\
f_{u}\left[\mathrm{~N} / \mathrm{mm}^{2}\right]\end{array}$ & $\begin{array}{c}\text { Strain at peak load } \\
\varepsilon u[\% \text { o }]\end{array}$ \\
\hline \multirow{2}{*}{ Mesh } & 6 & B500A & 513 & 540 & 29 \\
\cline { 2 - 6 } & 5 & B500A & 550 & 570 & 25 \\
\hline Strengthening & 6 & B500B & 476 & 550 & 96 \\
\hline
\end{tabular}

Properties of the welding. The setup to measure the weld strength is shown in Fig. 5 (a). In this setup, cross-shaped samples consisting of two rebars (Ø5.0 and Ø6.0 mm) welded perpendicular to each other were tested by pulling the longer rebar. The specimens were randomly cut of the mesh and the vertical and the horizontal bars were carefully removed by hand.

The welding resistance obtained from a total of 6 samples exhibited a huge scatter in the weld strength. Two samples achieved a resistance of less than $1 \mathrm{kN}$ (see Fig. 5 (b); specimens 5 and 6); these two samples were not taken into account for the determination of the mean value, as they had likely been damaged during preparation. This resulted in an average weld strength of $4.0 \mathrm{kN}$, much weaker than the meshes produced by the Mesh Mould tool-head which yields a weld strength of about $7.5 \mathrm{kN}$ with a much reduced scatter. 


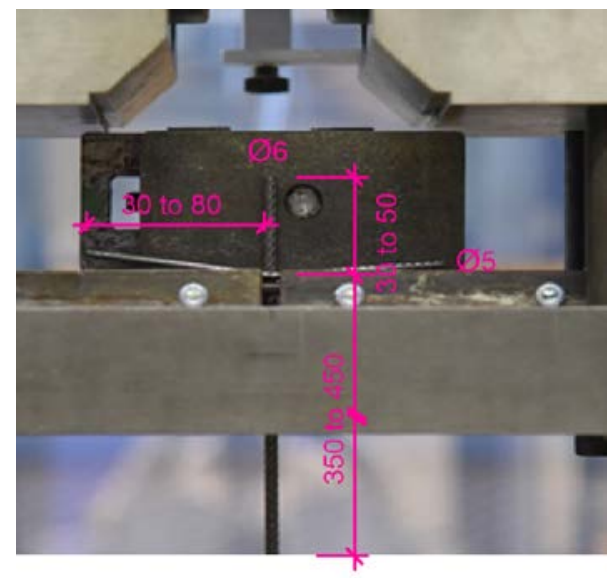

(a)

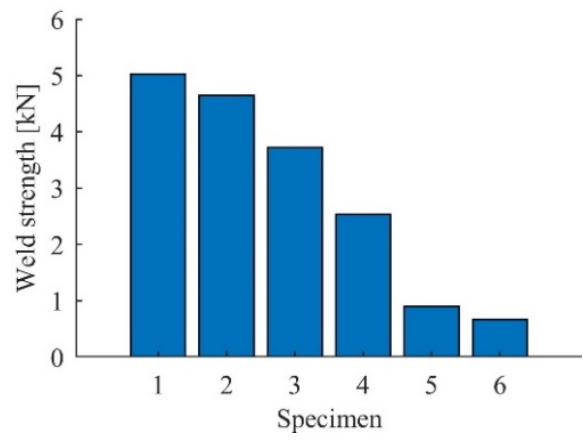

(b)

Fig. 5. (a) Setup of the welding test (dimensions in [mm]) and (b) results of the welding tests sorted by strength

\section{Results and Discussion}

\subsection{Predicted behaviour of the Mesh}

According to the results of the tension tests of the rebars and the weld strength, the welds are the weakest among the three possible failure mechanisms (see Fig. 3 (b)). The mean weld strength is only capable of activating $35 \%$ of the ultimate strength of the discontinuous direction and $22 \%$ of the shear strength in the perpendicular direction. Hence, the capacity is strongly limited by the welds and most of the reinforcement strength will remain unused. Moreover, the high scatter observed in the weld strength could lead to significant differences in the results of the bending tests for identical configurations.

The bending capacity of the samples without fibres reinforced with the welded mesh $(\mathrm{C}+\mathrm{M})$, can be predicted by means of cross-sectional analysis neglecting the concrete tensile strength, considering the reinforcement capacity limited by the mean welding shear strength (according to Table 1) and the concrete at maximum capacity in compression. The predicted bending strength $(0.70 \mathrm{kNm})$ is lower than the bending capacity of concrete $(0.97 \mathrm{kNm})$, consequently, the tested meshes do not fulfil the requirements for minimum reinforcement in these samples. If the welds were made by the robot of the Mesh Mould project, then a bending strength of $1.24 \mathrm{kNm}$ would have been possible, this would have fulfilled the requirement for the minimum reinforcement.

\subsection{Four-point bending test}

Figure 4 shows the results of deflection versus bending moment for the different tests. In this plot, the horizontal lines show: (i) the mean peak bending capacity of plain concrete, (ii) the mean peak bending capacity of the SFRC, (iii) the predicted mean capacity 
of the samples without fibres reinforced with the mesh and (iv) the independent combination of the peak strength of the fibres and the reinforcing mesh.

The bending strength of the samples without fibres reinforced with the mesh $(C+M)$ did not fulfil the requirements for minimum reinforcement in bending for the $80 \mathrm{~mm}$ deep elements as expected. Hence, these tests showed a softening branch after cracking with strain localisation. The cracking load of these elements corresponds to the results of the concrete samples containing no reinforcement at all. A post-peak plateau around $0.70 \mathrm{kNm}$ was observed as predicted when neglecting the concrete tensile strength. Only the continuous rebar located in the localized crack showed a visible plastic shear deformation due to the force transfer. It can be concluded that the welding strength limited the bending capacity.

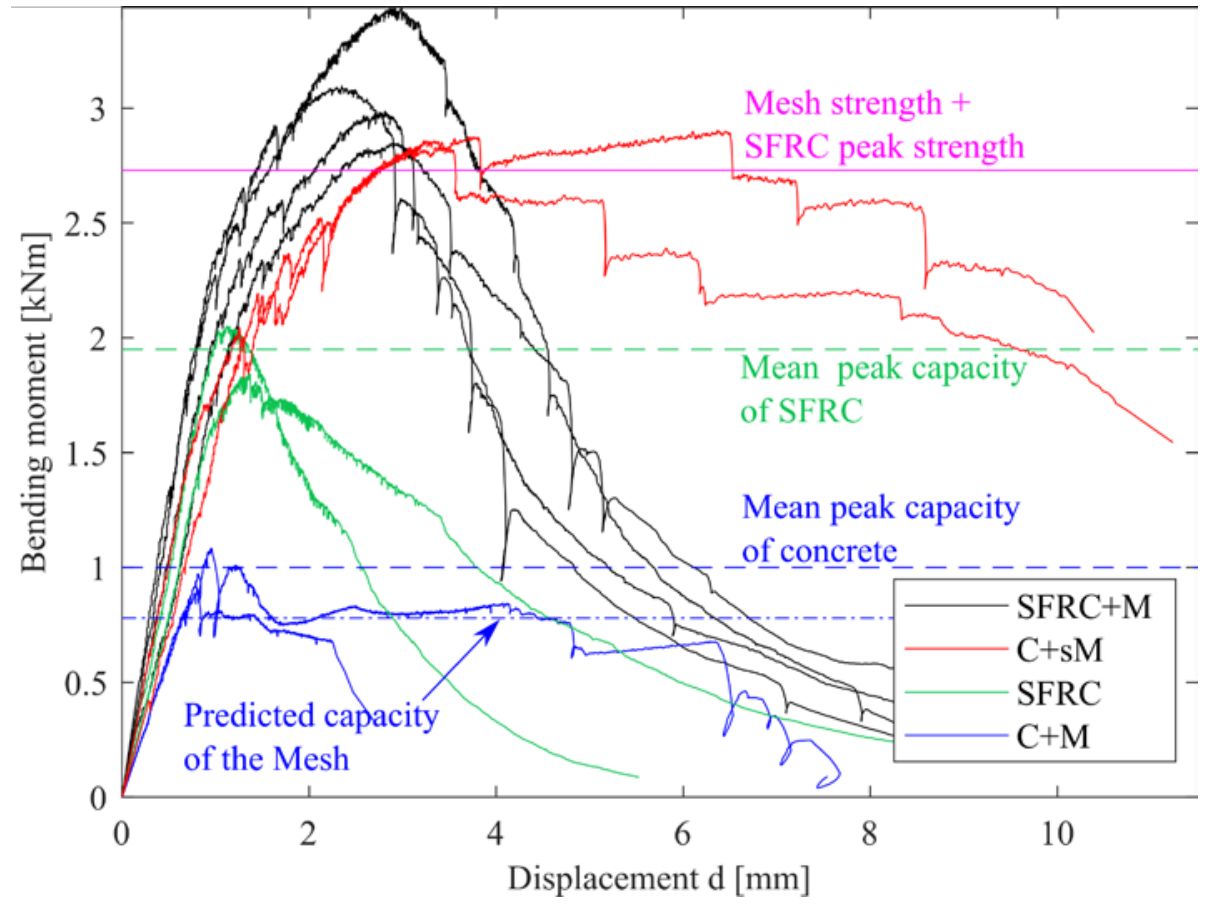

Fig. 6. Results of the four-point bending test of all samples

The configuration with fibres in addition to the mesh (SFRC+M) reached the desired deflection hardening and generated more cracks than the specimens without fibres. The ultimate bending strength increased significantly because of the addition of steel fibres. The capacity is $16 \%$ higher than the independent combination of the strengths of the SFRC $(1.95 \mathrm{kNm})$ and the mesh $(0.70 \mathrm{kNm})$ which is the residual strength of the $\mathrm{C}+\mathrm{M}$ samples and was exceeded by all 4 tested specimens. This result shows the beneficial effect of SFRC when adding reinforcement because a more distributed crack pattern is produced, avoiding premature local failure in the weakest section. The softening branch 
in the post-peak behaviour is a combination of the smooth fibre pull-out in the localized crack and sudden failures of welding spots.

The two specimens with two additional rebars $(\mathrm{C}+\mathrm{sM})$ reached a mean bending capacity of $2.89 \mathrm{kNm}$ higher than the predicted value around $2.50 \mathrm{kNm}$ based on a crosssectional analysis. Compared to specimens SFRC+M, the samples $\mathrm{C}+\mathrm{sM}$ show a lower peak bending capacity but a higher ductility. These samples exhibited 3 to 4 cracks between the load application points at peak load, all of them extending over more than $50 \%$ of the depth. In the post-peak range, the drops in the bending moment are due to subsequent failures of welds and finally a rupture of the strengthening rebars.

The beneficial effect of crack distribution on the performance of fibre reinforced concrete can be clearly seen in Fig. 7, which shows the crack pattern near the peak load of two identical samples including fibres in addition to the mesh (SFRC+M). The specimen with more distributed and thinner cracks (SFRC+M\#2, Fig. 7 (b)) reached a significantly higher capacity than the other specimens, which all showed a more pronounced strain location in a single crack (as SFRC+M\#1, Fig. 7 (a)). In spite of this observation, the insufficient weld strength did not allow developing the envisaged crack spacing of $30 \mathrm{~mm}$, with a crack at every transverse rebar. Hence, the observed behaviour of the mesh in this study is not representative of Mesh Mould structures, in which the stronger welding could lead to the envisaged distributed cracking and consequently a much better performance.

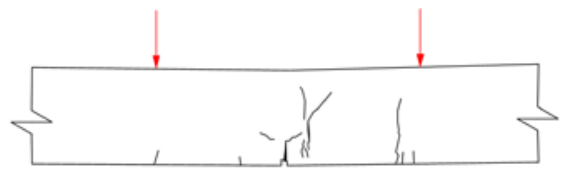

(a)

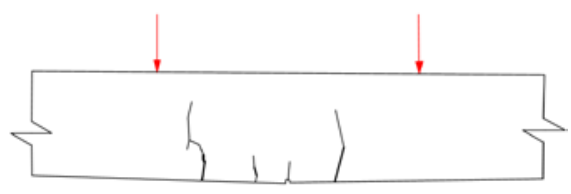

(b)

Fig. 7. Crack pattern near peak load: (a) SFRC+M\#1, $\mathrm{M}_{\mathrm{u}}=3.1 \mathrm{kNm}$ and (b) $\mathrm{SFRC}+\mathrm{M} \# 2, \mathrm{M}_{\mathrm{u}}=3.4 \mathrm{kNm}$

\section{Conclusions and outlook}

This research has shown the beneficial effect of steel fibres to improve the mechanical behaviour of Mesh Mould structures, in particular in its weaker horizontal direction. The use of steel fibre leads to a significant increase in strength and ductility. Moreover, it has been observed that the capacity of steel fibre reinforced Mesh Mould elements is higher than the combination of the individual capacity provided by the fibres and the Mesh Mould meshes. This effect is attributed to the crack width control produced by the steel meshes, which allows a better performance of the SFRC.

However, careful attention must be paid to this main conclusion. In this preliminary study, only one fibre type in combination with a tailor-made reinforcement mesh was tested in a four-point bending test. The findings might not be transferable to all types of fibre or volumetric contents and the topic remains complex. 
On a wider level, research is also needed to explore the possibilities of longer fibres for the application for Mesh Mould elements to more efficiently cause jamming during the filling process.

The use of Mesh Mould meshes with a higher weld strength would allow taking full advantage of the observed benefit of distributed cracking on the behaviour of SFRC, leading to a better performance than observed in this study.

\section{Acknowledgments}

This paper summarizes the results of a Master thesis carried out under research supported by the National Centre for Competence in Research in Digital Fabrication - Innovative Building Processes in Architecture (project number 51NF40_141853).

\section{References}

1. Hack, N., Lauer, W., Gramazio, F., Kohler, M., Blank, N.: Method of fabricating a 3-dimensional structure, mesh formwork element for fabricating a 3-dimensional structure, and method of fabricating the same, In: Google Patents, (2015)

2. Kumar, N., Hack, N., Dörfler, K., Walzer, A., Gonzalo, J. Gramazio, F., Kohler, M. Buchli, J.: Design, development and experimental assessment of a robotic end-effector for nonstandard concrete applications, In: 2017 IEEE Int. Conf. Robot. Autom., pp. 1707-1713, Singapore (2017).

3. Gebhard L.: Mesh Mould: Model Material Filling Study, Zürich (2017), (unpublished).

4. Hack, N., Wangler, T., Mata-Falcón, J., Dörfler, K., Kumar, N., Walzer, A., Graser, K., Reiter, L., Richner, H., Buchli, J., Kaufmann, W., Flatt, R., Gramazio, F., Kohler, M.: Mesh Mould: An on site, robotically fabricated, functional formwork. In: $11^{\text {th }}$ High Performance and $2^{\text {nd }}$ concrete innovation conference, Tromsø (2017).

5. Agustí-Juan, I., Müller F., Hack, N., Wangler, T., Habert, G.: Potential benefits of digital fabrication for complex structures: Environmental assessment of a robotically fabricated concrete wall, In: J. Clean. Prod., vol. 154, pp. 330-340, (2017).

6. DFAB HOUSE homepage, http://dfabhouse.ch/mesh_mould/, last accessed 2018/03/05.

7. Mata-Falcón J.: Mesh Mould structural tests, Zürich (2016), (unpublished).

8. Pfändler, P.: Potential of steel fibre for Mesh Mould elements, Zürich (2017), (unpublished).

9. DIN EN 14651: 2007 12: Prüfverfahren für Beton mit metallischen Fasern; Bestimmung der Biegezugfestigkeit (Proportionalitätsgrenze, residuelle Biegezugfestigkeit), Deutsche Fassung EN, (2007). 